Culture et histoire dans l'espace roman

4 | 2010

Les représentations du corps dans la litterature latinoaméricaine

\title{
Escritura de un canon corporal
}

Sobre Canon de alcoba de Tununa Mercado

\section{Marta Inés Waldegaray}

\section{(2) OpenEdition}

\section{Journals}

Edición electrónica

URL: https://journals.openedition.org/cher/8680

DOI: $10.4000 /$ cher. 8680

ISSN: 2803-5992

Editor

Presses universitaires de Strasbourg

Edición impresa

Fecha de publicación: 30 junio 2010

Paginación: 227-242

ISBN: 978-2-35410-007-0

ISSN: 1968-035X

\section{Referencia electrónica}

Marta Inés Waldegaray, «Escritura de un canon corporal», reCHERches [En línea], 4 | 2010, Publicado el 15 diciembre 2021, consultado el 25 enero 2022. URL: http://journals.openedition.org/cher/8680 ; DOI: https://doi.org/10.4000/cher.8680

\section{cc) (요 ()}

Ce(tte) œuvre est mise à disposition selon les termes de la Licence Creative Commons Attribution -

Pas d'Utilisation Commerciale - Partage dans les Mêmes Conditions 4.0 International. 


\title{
Escritura de un canon corporal. Sobre Canon de alcoba de Tununa Mercado
}

\author{
MARTA InÉs WALDEGARAY \\ Université Paul Verlaine, Metz
}

Deriodista, traductora, editora, escritora, la obra de la escritora argentina primeros relatos en Celebrar a la mujer como a una pascua, hasta su última novela en 2005, Yo nunca te prometí la eternidad, por la cual obtuvo en 2007 el Premio Sor Juana en México. Entre aquella primera publicación y la segunda, Canon de alcoba (1988), compendio de relatos que estudiaremos en el presente trabajo, transcurren 11 años. Dos años después (1990) publicará En estado de memoria, y a continuación, siempre con intervalos productivos de 2 años, vendrán en 1994 La letra de lo mínimo y en 1996 La madriguera. En 2003 publica Narrar después. Estas tres últimas obras se caracterizan por una unidad de estilo, que le es ya muy propia: la forma breve (relatos, miniensayos), la reflexión metaliteraria, la pincelada autobiográfica. El exilio, vivido en dos ocasiones por razones políticas, es la experiencia crucial que debemos tener en cuenta en su itinerario literario. El primero transcurrió en Francia (Besançon) entre 1966 y 1970, y el segundo en México, entre 1974 y 1987. Mercado escribe Canon de alcoba durante sus años de exilio en México. La marca autobiográfica, la espesura de la memoria como desafío narrativo, la dificultad formal de clasificar sus escritos dentro de categorías 
convencionales $^{1}$, son las tres dominantes de su literatura. Esta brevísima presentación de la escritora apunta fundamentalmente a establecer el marco temporal de nuestro análisis: la post-dictadura en Argentina² ${ }^{2}$

La mayor parte de las publicaciones de Mercado se realizan en un período de 8 años comprendidos entre 1988 y 1996, años en los cuales el campo literario argentino intentaba todavía reconstituirse luego de la dislocación intelectual producida por el golpe de estado de marzo de 1976. Al respecto conviene recordar que la dictadura gravó en la literatura argentina ciertas constantes temáticas focalizadas en el cuerpo, como la de la violencia política o sexual, el sometimiento, el encierro, el exilio, el desarraigo cultural y lingüístico, temáticas que fueron declinadas por diferentes géneros literarios, como el fantástico, el policial, la ciencia ficción o la novela histórica, y según representaciones figuradas, elípticas, alegóricas, metafóricas, mensajes cifrados en definitiva que fueron las formas (las máscaras) de representación asumidas por el corpus literario argentino en pleno proceso militar (Sarlo 1987: 30-59, Morello-Frosch 1987: 60-70, Reati 1992, Spiller 1993). Luego, en los años 80 y 90, las propuestas formales apuntaron a la desacralización y convocaron el humor, la farsa, la parodia, la sátira, la fragmentación, la reflexión metaliteraria (Gnutzmann 2006:4-5). Pienso en la corriente innovadora - con diferentes grados de experimentalismo narrativo - que para la literatura argentina de los 90 significó la irrupción de jóvenes escritores (rondaban entonces los 30 años) como Guillermo Saccomano, Rodrigo Fresán, Juan Forn, Alan Pauls, Daniel Guebel, Sergio Chejfec, Luis Chitarroni, Sergio Bizzio, Carlos Eduardo Feiling (De Mora 2003: 65-83).

1 Comenta Daniel Freidemberg sobre En estado de memoria: «No se trata de relatos, al menos en el sentido más habitual del término, tampoco de artículos ni de memorias, pero algo hay de todo eso, y también de ensayo y de confesión. Aparecido por primera vez en 1990, En estado de memoria no sólo rompía entonces con la noción de género literario o la desconocía drásticamente, sino incluso con la de literatura tal como se la suele entender. [...]». (Freidemberg 1999). En cuanto a los relatos de Canon de alcoba, declara Mercado en una entrevista: "Durante mucho tiempo lo sentí como un libro rechazado, castigado. Primero lo presenté al premio La Sonrisa Vertical de Tusquets. Al jurado le interesó y lo consideró bien escrito, pero el libro no habría tenido el "voltaje" requerido por la colección. En las editoriales mexicanas lo rechazaron de plano. Los textos no encuadraban en género ni en formato. Yo no hacía lo que se me pedía, lo mío no era porno, era demasiado variado, muy vago, no era novela, no era cuento, no era poesía... ». (Plante 2006). De regreso a Buenos Aires en 1987, el libro fue publicado por primera vez en 1988 por la editorial Ada Korn y ganó el premio Boris Vian, premio organizado durante la dictadura por un grupo de escritores argentinos.

2 Nos referimos a la última dictadura en Argentina, que tuvo lugar entre 1976 y 1983. 
El exilio fue por cierto en los 80 una recurrencia literaria y un debate intelectual directamente relacionado con la experiencia traumática de tantos intelectuales y escritores (poetas, novelistas, dramaturgos, cineastas) que se habían visto obligados a dejar el país, o bien que habían decidido permanecer en él éclipsándose (De Diego 2000: 431-458). Los que se fueron y los que se quedaron, los "barridos» afuera, y los "aplastados» adentro (como respondiera Cortázar en la célebre polémica que mantuvo con Liliana Heker en 1978)3 , alimentaron una controversia de carácter ético sobre el compromiso político desde la literatura. La noción de exilio interior intentó disolver el enfrentamiento con la intención de reconstruir un lugar común (una unidad, que rápidamente se volvió insustancial) de enunciación que condujera a restañar el campo literario argentino.

La obra de Tununa Mercado nos devuelve a esta literatura de escritores argentinos exiliados, pero con una singularidad, consistente en que el exilio en ella posee tanto un sentido real e histórico como figurado, si por figuración entendemos la transposición no mimética de una realidad física hacia una realidad diferente, o como diría Mercado, el «ejercicio de transportación» («Punto final», Mercado 1994: 117) de la experiencia o del sentido. Esta realidad existencial no ocupa el primer plano de realidad en sus relatos, es «la imperecedera nostalgia de otro espacio», pero también «un recordatorio de lo que no se ha vivido» (39), como puede leerse en «El sueño del primer exilio». Pertenece más a un orden pasado que al presente, más a lo que no fue, que a lo que pretende estar. Su figuración es la del sueño persistente con la ciudad ausente y su río, en detrimento de la pequeña ciudad francesa, del este, "ciudad casi alemana» (40), que se entrega al expatriado (a un yo refugiado en un nosotros) sin que él pueda apropiársela. El sueño es exhibición y encubrimiento a la vez. Una figuración que vuelve reversible la experiencia del exilio, y que en todo caso, la exilia de todo ejercicio de testimonio. Si la lengua es el territorio de residencia de todo escritor, o como lo expresó, ya de manera célebre, Theodor Adorno (1984: 87) con respecto al escritor en exilio: «En el exilio la única casa es la escritura» - lo cual implica asignarle

3 Esta polémica fue publicada en Cuadernos Hispanoamericanos (1993: 590-604) bajo el título «Polémica sobre el exilio». La siguiente cita extraída de la respuesta de Heker a Cortázar dará el tono de la polémica: «No somos héroes ni mártires. Ni los de acá ni los de allá. El alejamiento, la permanencia en el propio país, en sí mismos, carecen de valor ético. [...] Se puede ser un traidor adentro o afuera, un gran escritor en el propio país o en el extranjero. Se puede asumir una perspectiva nacional aun en el exilio y escribir desde la torre de marfil en el propio suelo. Qué hizo, qué hace un escritor con sus palabras, ésa es la cuestión última.», p. 595. 
a la lengua en exilio una capacidad regenerativa, de territorialización, esto es: de fundación de un espacio compensatorio y protector con respecto a las contingencias externas -, si la lengua en exilio entonces territorializa, el fundamento de valor estético de la lengua en literatura ¿no radica acaso en transgredir la norma, en contravenir el canon, en desterritorializar? La obra de Mercado revoca incontestablemente las territorialidades en materia literaria al ampararse en la diversidad genérica y en la reflexión teórica sobre la escritura.

\section{Cuerpo y exilio}

Asociar la experiencia del exilio a la literatura es fundamentalmente, y ésta es nuestra perspectiva, entroncarla a la experiencia de la escritura, más precisamente: a la escritura como experiencia. En tal sentido, el exilio en literatura es menos el lugar geográfico desde donde se escribe un texto, que un lugar de residencia enunciativa. Si nos detenemos en la tematización narrativa del exilio, la crítica (Astutti 2005, Jara 2005-2006: 7-16) reconoce que la carencia, la pérdida, la desprotección, el desarraigo, la fractura de la identidad, la inestabilidad geográfica y lingüística (todo esto magistralmente compendiado en Yo nunca te prometí la eternidad, 2005), son temáticas ${ }^{4}$ constantes en la narrativa de Mercado, aun en aquellos otros textos no escritos en tales condiciones. Pero si interrogamos la manera en que la experiencia modifica el ámbito de la escritura (entendida ésta como organización verbal de un espacio imaginario), y es aquí donde preferimos detenernos para analizar el trabajo de Mercado, veremos que la subjetividad eclipsada de sus relatos, el despojamiento que caracteriza a sus personajes, no son narrados desde una perspectiva realista, ni testimonial. En Canon de alcoba por ejemplo, la realidad que estos relatos despliegan es una experiencia reacia a toda explicación racional. Los relatos narran una intensidad, la intensidad de una experiencia corporal, la del deseo. La escena de estos relatos es el cuerpo, desnudo o dejándose entrever; el cuerpo capturado en su estado de deseo. La desnudez no es aquí sinónimo de desamparo.

Canon de alcoba: título enigmático que preludia la armonía poética de la obra. Dos definiciones, que escindirán el título en dos, introducen la lectura del volumen. Canon y alcoba.

4 Temática, no concebida como un a priori al texto y al trabajo crítico (lo que llamamos tema), sino como una interpretación elaborada de la historia (Jitrik 1987: 26-27). 
Canon (lat.canon). Fuga denominada perpetua, en la que las voces van entrando sucesivamente, repitiendo cada una el canto de la que la antecede. Norma. Regla. Precepto sobre la manera de hacer algo.

Alcoba (del árabe al-qubba), la cúpula, la bóveda, el gabinete. Aposento destinado para dormir. Antiguamente, tertulia que los virreyes de México tenían en su palacio.

Diccionarios

La noción de canon presente en el título y afirmada en el epígrafe, nos reenvía por un lado a la armonía musical, por otro lado también, a la idea de tradición, de modelo, esto es, en sentido amplio, al mundo de las formas literarias. La alcoba representa un espacio privado y de recogimiento interior que, según leeremos, será el universo escénico de la mayoría de los relatos. Ambos definirían maneras canónicas de ser y de hacer, y su asociación nos induce a sospechar el encuentro con un canon de conducta amorosa, y también, con un modelo erótico, el literario, una literatura que por codificación genérica agiganta, cuantifica, instrumentaliza, dilata, ofrece apoteósicos finales, y hasta aspira a presentarse como guía de aprendizaje práctico de un saber hacer corporal que reposa, doblemente, tanto en la instrucción ejercida por alguien que se encuentra en situación y en posición de dominación, como en la optimización del placer (Mercado 1994: 58).

Estos relatos, 28 en total, presentados en 7 secciones, ofrecen la escritura de experiencias de intimidad, de lo más íntimo de la intimidad, esto es: de la experiencia corporal del deseo erótico. Exploran dos tradiciones narrativas: la de la forma breve ( 7 de ellos son verdaderos micro-relatos $)^{5} \mathrm{y}$ la de la literatura erótica. Las intimidades de la alcoba son un juego plural y adulto que convoca deseos, preámbulos, incitaciones, técnicas amatorias (ni grotescas, ni perversas), encuentros homo y hétero-eróticos, onanismo sensual, excitación a distancia, escuchas, miradas, pérdidas o ausencias que excitan la imaginación y exaltan el recuerdo de un encuentro físico. La sexualidad es el espacio privado en el cual el individuo se recorta de lo público exterior; es de algún modo la fortaleza vital desde donde construir una esfera subjetiva e impersonal. El cuerpo ofrece (a)tajos desde donde afirmar esta propensión hacia la despersonalización y despojamiento de los personajes, sorteando la contención sentimental del subjetivismo. Es en tal sentido que estos relatos se abstraen del peso de la anécdota y le permiten a la escritura su pasaje hacia la reflexión metaliteraria, hacia el análisis de una

$5 \mathrm{Al}$ respecto puede consultarse «Hacia una teoría del microrrelato hispanoamericano", artículo en el cual David Lagmanovich estudia la tradición de la forma breve en la literatura latinoamericana (Lagmanovich: 1996.) 
encrucijada de estatuto narrativo. Cómo figurar el deseo, cómo narrarlo: «¿La vida del cuerpo se ordena siempre como un espectáculo?», se pregunta Mercado en «El próximo recodo» (106). El imperio de la acción incauta o sutil de mirar al otro para retenerlo en su objetividad, en su corporeidad, entraña la volatización del yo, su desaparición como lugar de enunciación y de la experiencia narrativa. La narración parece suspenderse. La observación se agudiza. En el programa poético de Mercado la narratividad se aplaza. «El deseo no es narrativo» (99) y la escritura "es un juego imaginario de constante búsqueda» (101) nos dice Mercado en su relato "Variaciones». En La letra de lo mínimo (1994), recordemos, considera que "escribir es quitar pieles, descorrer membranas, apartar tejidos y epitelios, desarticular la fusión de letra y sentido, deshacer la escritura para hacerla y deshacerla hasta el infinito de la línea» (25). Narrar después (2003) es el título del sexto de sus libros, compuesto por ensayos breves. La captura del deseo, la retención del placer, afinan la práctica de la observación, y la observación convoca a una representación explícita pero no grosera de la sexualidad. El cuerpo a cuerpo o la proximidad declinada en sus múltiples formas de roces, caricias, penetraciones, es la materia primera de estos relatos. En ellos la mirada asume un rol organizativo central para una percepción que comprende tanto el acto de percibir como el mundo percibido, puesto que si la mirada registra, describe, escruta, también reflexiona acerca de su realización como acto. La visión permite despegar de la materia narrada, la mirada supone una distancia indisolublemente ligada al ángulo particular desde el cual se percibe. Ver es una percepción comparativa, y en tal sentido el principio mismo de la objetividad. Si el sentido de la audición nos envuelve («oír el amor es oír hacer el amor», 32), la mirada nos distancia. Los relatos escenifican una y otra vez el sentido de la mirada a través de la presencia de ojos que ven y de cuerpos que se exponen libertina o sensualmente a la mirada ajena. Es el caso de los exhibicionistas que muestran sus penes a los paseantes en Espejismos I, II, III (aunque en el último relato, por un error de percepción, el sexo que el hombre retiene en su mano resulte ser una pera), o del ritual de excitación masturbatoria en "Ver», escena observable a través de dos ventanas que ubicadas frente a frente permiten «dominar la vocación de ver [...] El sexo en el centro de la escena» (29). En todo caso, quien percibe la exhibición del goce ajeno se encuentra objetivado o a veces radicalmente fuera del centro de la escena. En "La casa del amor», primero de los relatos de Eros, la quinta de las secciones, colores, trazos, formas y materias despiertan la energía del deseo que la mirada contemplativa y atenta dispara en un espectador que se encuentra dentro de un museo. «El deseo entonces 
no es cuestión del Eros acoplador, "unificador"» (66). Los mensajes visuales transgreden la normalización de la mirada que la organización del museo se propone establecer. Extrañamiento en la normalización o normalización de lo extraño cuando se trata de encuentros homoeróticos femeninos («El recogimiento»), que pueden convocar la presencia pasiva o activa de un tercero no inocente ("Oír», "Las amigas»). Lo que estos relatos escenifican es el despegue operado entre un lugar de enunciación que da cabida a la reflexión metaliteraria, y la materia narrada. El primero de los relatos, «Antieros», lo expone magistralmente. En él la enunciación se desencarna, gramaticalmente hablando, puesto que no reposa en ningún pronombre. Como si se tratara de una receta de cocina, la escritura fluye a través de una serie continua de infinitivos que describen la tarea doméstica matinal y cotidiana de una figura femenina que, entre los vapores que desprenden las ollas de la cocina, las fragancias de los alimentos frescos y de la limpieza, se autoerotiza :

[...] esa atmósfera pura de limpieza que exalta los sentidos en la sala [...]. Sacarse los zapatos para sentir la frescura cálida del terciopelo. Llevar la mano derecha suavemente desde la pantorrilla hasta el muslo y acariciar confirmando que esa piel puede perfectamente competir con la pana; no subir más arriba la mano; desprenderse la blusa y dejar unos momentos los pechos al aire, erguirse y, con la mano en jarras, mirarse el perfil en el espejo del fondo de la vitrina por entremedio de las copas de cristal. Salir de la sala $\mathrm{y}$, previamente, cerrar la camisa, abotonarla y reacomodar los pliegues de la falda bajo el delantal. (13)

Los infinitivos revelan un aplazamiento narrativo; dan cuenta de una forma vacía o desviada de enunciación en la cual la subjetividad se extravía: «Quien limpia no debe mirarse en el espejo» (12), y podríamos agregar que quien escribe tampoco:

Quien describe organiza los espacios sobre los que la palabra va a actuar [...] ese es su recurso, su escudo, su defensa: situarse afuera, en el ángulo oculto desde donde se puede fisgonear la escena [...] necesita lanzar el trazo, arrojar la línea, despedir la frase como un pintor que pone los óleos sobre la tela para luego apartarse de la obra, ocultando su mano que antes no había vacilado en develar todo pudor y hacer de él todo deseo. (106)

El relato inaugural escenifica la ausencia de una voz protagónica gramaticalmente anclada, distanciamiento que caracterizará todo el volumen. Otro ejemplo, el comienzo del quinto de los relatos, «Ingleses»: " $\mathrm{Ni}$ siquiera pensar ahora en los viajes por el continente, ni en las más remotas islas anteriores al exilio» (24). A través de estos infinitivos, de las ausencias verbales, de la indeterminación de la voz narrativa, la literatura de Mercado 
escapa a todo principio de individuación, de identidad. La concepción canónica del personaje se resiente y esta inadecuación formal es observada en «El próximo recodo»:

- ¿Figuras? Pero ¿cuáles figuras? ¿Se puede dibujar con ellas un concepto que anega las resoluciones [...] No serían las variedades masculina y femenina [...] No una diferencia marcada por contrarios enfrentados ni las formas absolutamente androides cuya diversidad binaria tranquiliza la razón. (106)

- Sin figuras ¿puede haber escenario, actuación, auto, ritual? ¿Y si se pensara que la palabra es el cuerpo? (107)

- Figuras, entidades: es difícil la búsqueda de una forma que no representara sino que supiera decir esa titilación permanente de los cuerpos [...]. (108).

Si bien estos relatos desafían la noción canónica de personaje, también es verdad que ponen al sujeto, desnudo, en el centro de la escena literaria y funcionan alrededor de él. La experiencia se ancla en una dimensión corporal cuya desnudez es aquí menos signo de carencia radical o simbólica (representación del exilio) ${ }^{6}$, que fuente de placer, retorno a una energía primera de vida. Esta centralización evidencia que la intimidad es aquí el lugar de residencia de la subjetividad, y el cuerpo, el recinto en el cual se aloja y del cual se debe extraer el sentido con el cual reparar, reconstituir, lo ausente. Lo que decimos se explicita en "Amor delirante», del cual citaremos dos breves pasajes:

- Cuando ella oía su voz algo cambiaba en su vida. Opaca, convincente, la dejaba entrar en su cuerpo y allí la recogía, en una especie de reserva interior que podía o creía poder almacenar para épocas de carencia. (85)

- De la contemplación pasaba al estupor, de la extrañeza a la desesperación, enloquecida por la perfidia de ese cuerpo estampado en la pared y empeñada en extraer de él un sentido que dijera algo más que el cuerpo que lo producía. (88)

6 Significación simbólica estudiada por reconocidas lectoras de Mercado como Adriana Astutti (2005), Sandra Jara (2005-2006: 7-16) y Carolina Rocha (2001: 19-26). A modo de ejemplo, nos parece que Canon de alcoba escapa al comentario de Sandra Jara con respecto a En estado de memoria, cuando concluye: «Entonces, si la desnudez había revelado un cuerpo exiliado de sí mismo descorporizándolo, y la carencia la dimensión de su vacuidad, ahora, la imagen del espejo objetivada - otro identificable pero no identificatorio -, expresa una mera apariencia que habla de la desmaterialización más absoluta. En síntesis, la desnudez, la carencia y la imagen en el espejo, pasan a constituirse en los recursos que Tununa Mercado articula para trazar el destino inexorable de una subjetividad fugitiva, (des)encarnada en el cuerpo del exilio » (6); o bien cuando se refiere a un «cuerpo condenado al autodesconocimiento » (6). Pensamos que en Canon de alcoba existe un yo exiliado de sí mismo en la medida en que su reino interior está vaciado de referente personal, lo cual pone en jaque al canon autobiográfico. 
Cuerpos entregados a la sensualidad del placer, sustraídos de la esfera pública y encerrados en alcobas. Desaparición pública y fuga de la identidad. Desaparición pública, pero no desaparición de lo público. Es justamente a través de estos términos: desaparición, público, por donde la historia reciente se cuela para hacerse un lugar en la tercera parte titulada "Realidades", constituida por cuatro relatos. En el primero de ellos, «No saquemos el ojo », brazos, pecho, un cadáver, la sangre derramada «negociada finalmente» (57) dan cuenta en un lenguaje cifrado de la ética revolucionaria. Tres son los cuerpos presentes por ausencia en este relato: el de un militante desaparecido, el cuerpo ya lejano de la abanderada de los humildes ( «la muertita rodeada de sus humildes», 58), y un cuerpo retirado, ausente, el del Viejo («El Viejo nos va a responder», 58) ${ }^{7}$. Se trata nuevamente, aunque desde otro contexto, de agudizar la percepción, de tener el ojo alerta («No bajen la guardia, no saquen el ojo de la mira, no desvíen la boca del arma»,57), de no sellar el cuerpo de la Historia («Todo está igual, no hay cierre, aquí nada se cierra, no hay punto final», 58). En el siguiente relato, «Asamblea», leemos el esfuerzo de una militante política por mantener la palabra en una asamblea («el discurso trastabilla», 59; «La sodomía sube de tono, incita al combate», 60). «En qué lugar», tercer relato, deformaciones, excrecencias y protuberancias corporales crean por estigmatización un colectivo ( Somos cientos de miles», 61) cuyo destino social es la exclusión («Nos objetivan en seminarios $[\ldots]$ no ocupamos un espacio que naturalmente debiéramos ocupar», 61). El último relato, «Fragmentos de una reflexión del general», convoca el problema de la descendencia política del General decepcionado por la malograda conducta de sus jóvenes militantes ( Esos muchachos se me han subido encima [...] No quiero hijos ni entenados», 62). Realidades nos trae el cuerpo de la Historia, el cuerpo social y político, el cuerpo de las víctimas.

Cuerpos sin nombre (sin identidad manifiesta), podríamos pensar en no-sujetos sujetados carnal o figuradamente a otros cuerpos, a través de la cópula, la caricia ( Amor desaparecido»), la mirada («Ver», «Pájaros»,

7 Sin ser explícitamente nombrados, estas alusiones se refieren a Eva y al general Juan Domingo Perón. 
«Pero todavía vibra»), la escucha ("Oír»), el consuelo del recuerdo y de la imaginación sublimada de aquél que alguna vez se poseyó («Amor delirante»), las fantasías con un tercero invocado («Teoría del amor»), la búsqueda del goce retenido y confundido con el cuerpo de la letra («Variaciones»), la filiación imposible («Fragmentos de una reflexión del general»), la delectación física que entrega la palabra («Amor discursivo»). Como necesitando confirmar la existencia del cuerpo deseado, el dedo (correlato erótico de la pluma del escritor), recorre su superficie («Un dedo se desliza, abre el círculo de la o. La o se entrega [...]», (92); «No se precipita el dedo en reconocer la piel $[. .] », 102$.$) y reconoce huecos, grietas,$ orificios, faltas todas restituidas por el placer que la sensualidad procura. La experiencia física es un terreno de reconocimiento, de apropiación de los sentidos, de confirmación quizás de un ya no ser, pero de una sobrecogedora revelación de estar vivo. Los relatos escenifican esta puesta en acto del mirar y del modelo que se expone, se deja mirar, oír, presentir, a través de un modo de mirar generalmente sesgado por una perspectiva narrativa esfumada, con un sujeto de la enunciación eclipsado, como exiliado, corrido, ensimismado o fuera de foco, acomodado en las penumbras o en la visión deficiente. Citemos:

- Para mirarla con comodidad hay que apagar las luces un rato antes, situarse en el centro del espacio de observación, en este caso la sala de un departamento del siglo diecinueve. La penumbra es la única condición para mirar $[\ldots](«$ Ver», 26)

- Ese encapsulamiento del amor en la alcoba crea una realidad propia, que se vive de los párpados hacia adentro [...] («Oír», 33)

- Ciudad extranjera, se entregaba, se ofrecía pero la mirada entonces resbalaba por sus piedras y sus árboles, sin mirar, enceguecida [...] («El sueño del primer exilio ", 39)

- La fronda apenas se agita, del verde se desprenden verberaciones que nos hacen entrecerrar los ojos. («Juicio final», 41)

- Cuando la mirada podía precisar sus contornos, lo que primaba era el color rosado del pelaje $[\ldots]$ un oleaje de verde que transmite desde allí ramalazos de humo que el ojo no alcanza pero adivina $[\ldots]$ («Pero todavía vibra», 53)

8 Este relato, que se presenta como una minuciosa descripción del paso de unos caballos sin jinetes que se alejan galopando por una avenida arbolada, bajo el sol, sudorosos, con sus crines erguidas, vibrantes sus cascos, fue para sorpresa de su autora seleccionado por Margo Glanz para un número especial de la revista de la Universidad Autónoma de México dedicado al erotismo y a la pornografía, en virtud ya no de su contenido sino del valor obsesivamente meticuloso de la descripción de la masa corporal en movimiento. (Plante 2006). 
- Pero lo que viene a poner el deseo en movimiento es un contraste entre el adentro y el afuera, la penumbra y la luz confundidas en el ojo [...] («La casa del amor», 66)

- Contra toda retórica de la luz esgrimida como un beneficio para el amor, las penumbras legitiman la dimensión pura del tacto, el vértigo del olfato $[\ldots]$ («Teoría del amor»,69)

- La entrada de los hombres siguió a una displicente apertura de las cortinas, cuando ya se acababa la tarde ( $(\text { Las amigas», 93) })^{9}$

Esta visibilidad insuficiente nos recuerda el mirar de reojo, o la mirada bizca, que Sigrid Weigel (1986: 69-98) teoriza; una mirada reconocida por las lecturas analíticas del gender ${ }^{10}$ como una estrategia femenina de escritura, inherente a un sujeto femenino que, para representarse de una nueva manera, decide reposicionarse. El estrabismo o duplicidad de esta mirada estética y feminista consiste, según lo entiende Weigel, en observar con un ojo una cultura patriarcal cuyas normas, roles y expectativas genéricas rechaza, y con el otro ojo, independiente y desenvuelto, atisbar nuevos modelos femeninos. No entraremos de lleno en este terreno cuyas claves de lectura nos son ajenas, pero diremos escuetamente y con cautela que, a nuestro juicio, esta orientación de la crítica literaria asume a menudo el riesgo de un tono reivindicativo de lo erótico femenino, asentado sobre categorías dicotómicas de reflexión que reducen el análisis crítico al marco

9 Esta serie de ejemplos no es exhaustiva.

10 Entiendo por gender, expresado de manera amplia y general, el marco crítico que se interesa por la configuración de una subjetividad marginal (femenina, homosexual) y que problematiza la categoría de género. Los estudios literarios que responden a esta orientación interrogan las representaciones del cuerpo-sexo-género y sus relaciones con la esfera político-cultural. Las escritoras latinoamericanas tienen en estos años 80 y 90 una notable presencia en el campo literario regional. Logran por cierto hacer cuña en herencias literarias de corte masculino. En el campo literario argentino, esta orientación patriarcal se revela en la famosa interrogación que Ricardo Piglia desliza en la novela que inaugura la década de los 80 en Argentina, Respiración artificial, cuando uno de sus personajes, desde el exilio, escribe: «A veces (no es joda) pienso que somos la generación del 37. Perdidos en la diáspora. ¿Quién de nosotros escribirá el Facundo?» (Piglia 1980: 94). En Argentina, Tununa Mercado pertenece a esta constelación literaria femenina, junto a Angélica Gorodischer, Hebe Uhart, Luisa Valenzuela, Marta Traba, Noemí Ulla, Diana Bellesi, Susana Silvestre, Liliana Lukin, Ana María Shua, María Rosa Lojo, Matilde Sánchez, entre muchas otras valiosas escritoras. En el ámbito latinoamericano, pensemos en Ana Lydia Vega, Rosario Ferré, Elena Poniatowska, Cristina Peri Rossi. También en el éxito editorial de Isabel Allende, Laura Esquivel, Ángeles Mastretta. (Salvador 1995). Una enumeración más completa y organizada resulta aquí imposible. 
pre-fijado ${ }^{11}$. La confianza abusiva o automática en el margen, en lo marginal o en lo marginado como lugar de residencia de una variante o de un doblez que entrañaría de por sí la expresión de la resistencia ¿no significa acaso una nueva operación de esencialización?, ¿no comporta tal vez la marca de un mero cambio de signo, esto es: de una inversión que tiende a restablecer y a naturalizar, dentro de la estructura, el campo de operaciones que pretendía desmontar?, ¿no entraña casi irremediablemente una lectura reduccionista de la dominación? No sólo el género como operación hegemónica interviene en una dinámica de poder (Domínguez 1998). Dar cabida al contexto cultural de enunciación se impone como necesario a fin de evitar caer en empirismos determinantes para el trabajo crítico. Preferimos hablar entonces de un lugar de enunciación fuera de foco, obsceno si se quiere (esto es, fuera de escena) y de configuración de una subjetividad sesgada, lo cual sin negar el interés que la literatura de Mercado suscita para los estudios feministas (Jara 1996), apunta más bien a rescatar la presencia de un punto de vista descentrado desde el cual se estaría ladeando toda mirada canónica: la de la gran literatura, la de los compartimentos genéricos, la de los escritores-faros generalmente masculinos, la de las grandes lecturas de la Historia (cuya figura paradigmática es en el campo literario argentino de los 90, Andrés Rivera).

11 Como ya lo dijera Josefina Ludmer en su pionero trabajo de 1985, «Las tretas del débil», a propósito de las estrategias discursivas de Sor Juana Inés de la Cruz en su «Respuesta a Sor Filotea», conviene evitar el señorío de las identidades previas al texto: "No hablaremos de la literatura femenina con rótulos ni generalizaciones universalizantes. Con esto queremos decir que rechazamos lecturas tautológicas: se sabe que en la distribución histórica de afectos, funciones y facultades (transformada en mitología, fijada en la lengua) tocó a la mujer dolor y pasión contra razón, concreto contra abstracto, adentro contra mundo, reproducción contra producción; leer estos atributos en el lenguaje y la literatura de mujeres es meramente leer lo que primero fue y sigue siendo inscripto en un espacio social. Una posibilidad de romper el círculo que confirma la diferencia en lo socialmente diferenciado es postular una inversión: leer en el discurso femenino el pensamiento abstracto, la ciencia y la política, tal como se filtran en los resquicios de lo conocido. Hablaremos de lugares [...]» (47). Dice inclusive Mercado sobre Canon de alcoba en una entrevista: «En mi libro no existió la reivindicación como premisa. La sexualidad femenina no necesita ser establecida ni reivindicada por nadie. [...] Obviamente que bordar, coser, tejer, cocinar son tareas proverbialmente de mujeres, pero no definen una escritura por el hecho de que aparezcan en un texto. Eso sería pueril. ¿Sería masculino un texto que describiera un motor como si se tratara de un trabajo de filigrana textual?». (Marianella Collette 2007) 


\section{Cuerpo y escritura}

Los relatos de Canon de alcoba son escenas fugaces de explícita sensualidad y carga erótica. Son breves relatos distanciados del grosero trazo pornográfico por el minimalismo que caracteriza la escritura de Mercado, una escritura siempre atenta a lo pequeño, a la filigrana del detalle, al acertijo de la palabra, a la incertidumbre de la página en blanco. La palabra, saturada de pasión amorosa, se dirige de manera narcisista hacia su propio poder de exploración revelando así su materialidad o corporeidad. La última de las secciones, "Amor Udrí»" ${ }^{12}$, compuesta por tres relatos, da cuenta de esta reflexión metaliteraria de una manera más singular que en el resto del volumen. Hacia el final entonces, la escritura se vuelve introspectiva y marca su territorio. La mano, el dedo moroso, operan el pasaje de sentido de un cuerpo a otro, del cuerpo del amante al cuerpo de la letra. Algunos ejemplos:

- El tacto precisa de la demora, de la dilación de la postergación, del detenimiento, del señalamiento sobre el territorio. Irreductible a la descripción, escapa a la imagen, se niega a la metáfora y más aún a la clasificación. Sólo existe aquello sobre lo que ejerce su cifra; sólo la marca, el hito. («Variaciones», 102)

- La palabra, soplo, aliento del alma, es cuerpo en la escritura. Aparece, rueda por los espacios en blanco [...] Palabra que decae, enferma hasta la extinción $\mathrm{y}$, de pronto, renace, como el amor udrí se reproduce, repta, avanza, se tensa $[\ldots]$ («El próximo recodo», 107-108)

«Punto final», el último de los relatos, recupera todas las series tendidas. El punto final que resuelve una sintaxis, concluye un relato, o cierra un libro, reenvía al lector argentino a un capítulo no definitivamente acabado de nuestra historia que jurídicamente pretendió congelarse. Mercado declara discretamente en este último relato su propósito poético, "poder realizar mediante argumentaciones la metáfora» (17). Se trata en realidad de una analogía declinada en dos tiempos. En primer lugar, la analogía del

12 El primero de los relatos de esta última sección se llama «Variaciones». Posee dos epígrafes en los cuales se citan versos del poeta español Fernando Quiñones (1930-1998), y una nota al pie en la cual se explica que esos versos corresponden a su poema "Amor Udrí» perteneciente a Las crónicas de Al Andalus (1970). En esta obra Quiñones regresa a la poesía amorosa de la Andalucía hispanoárabe, a las jarchas, moasajas y zéjeles (Díez de Revenga 2006: 605). En esta última parte entonces, Mercado rinde tributo a la castidad del amor preconizada por el amor udrí, a la obstinación del deseo, a la unión intelectual del deseo y su lengua(je). Lo que esta referencia literaria anuncia es la conversión final de la motivación erótico-carnal en afición poética. 
bordado y la escritura, del tejido y del texto, una analogía que encuentra en ambas prácticas (tejer y escribir) un movimiento maquínico común, un sistema productor que se asemeja a la cadencia repetitiva del golpe-pausasilencio. En un segundo lugar, la analogía establecida entre la escritura y el amor, asociación que emergería cuando la precaución sintáctica decae y se entrega (como el amor) al descontrol, al desmadre. En la medida en que la mirada sondea un sentido, la indagación sobre el acto de escribir se impone en Mercado; podría entonces hasta decirse que esta observación se vuelve estrategia argumentativa. Desde los avatares de la sexualidad, el cuerpo se erige en Mercado en lugar de exilio del yo, de su desvanecimiento, así como en metonimia del tránsito de sentidos operados entre la sensualidad corporal y el hedonismo literario.

El cuerpo resulta ser en Canon de alcoba origen y fin del lenguaje; es el espacio figurado (el cuerpo de la letra) desde el cual se representa a la palabra en su proceso de creación y de significación. Desde el lugar conferido y aceptado de la noción de canon (genérico-literario: la forma breve, la literatura erótica; pero también genérico entendido como gender), Mercado elige situarse en lo más propio, íntimo y cercano: el cuerpo y sus placeres, mudando no sólo la alevosía de una literatura erótica que magnifica, sino también su sentido mismo, esto es: la posibilidad de conocimiento de lo que en ese marco se decide alojar. Porque cuando la intimidad se presenta como panorama de lectura de otras prácticas y discursos (la escritura, la política, la subjetividad), la privacidad de lo íntimo se relativiza, si no se desvanece. Estos textos evocan el placer carnal desde el deleite verbal. Piensan lo erótico, lo público, lo subjetivo, desde el lugar otro de la escritura. Y la trascendencia de la escritura, desde la entrega corporal. He aquí lo sintomático de este moroso trabajo de deleite poético menos representativo que perceptivo, menos premeditado que meditado, menos literario que escritural.

\section{Bibliografía}

Adorno, Theodor W., 1984, Mínima Moralia, Londres, Verso.

Astutti, Adriana, 2005, «Intimidad y desamparo: Tununa Mercado», in Boletín/12 del Centro de Estudios de Teoría y Crítica Literaria, Rosario, Universidad Nacional de Rosario, diciembre 2005. 
Online: http://209.85.229.132/search?q=cache:1Q0AU54A6WMJ:www.freewebs. com/celehis/actas2004/conferencias/E/1_Astutti.doc+intimidad+y+desamparo+ tununa + mercado + rosario $\& \mathrm{~cd}=1 \& \mathrm{hl}=\mathrm{fr} \& \mathrm{ct}=\mathrm{clnk} \& \mathrm{gl}=\mathrm{fr}$

De Diego, José Luis, 2000, "Relatos atravesados por los exilios », in Noé Jitrik (ss dir.) Historia crítica de la literatura argentina, Buenos Aires, EMECE Editores, p. 431-458.

De Mora, Carmen, 2003, «El cuento argentino de los años 90 », in Geneviève Fabry - Ilse Logie (ss dir.), La literatura argentina de los años 90. Foro hispánico. Revista hispánica de Flandes y Holanda, Amsterdam - New York, n²4, Rodopi Ed., p. 65-83.

Díez de Revenga, Francisco Javier, 2006, «Fernando Quiñones y el modelo de "crónica poética"", Revista de Literatura, julio-diciembre, 2006, vol.LXVIII, $\mathrm{n}^{\circ} 136$, p. 597-610.

Online: http://revistadeliteratura.revistas.csic.es/index.php/revistadeliteratura/ article/viewFile/22/24

Domínguez, Nora - Perilli, Carmen, 1998, Fabulas del género. Sexo y escrituras en América latina, Rosario, Beatriz Viterbo Editora.

Freidemberg, Daniel, 1999, artículo para Revista Ñ, Clarín, Buenos Aires, domingo 7 de febrero de 1999.

Online: www.audiovideotecaba.gov.ar/areas/com_social/audiovideoteca/literatura/ mercado_bio_es.php

Gnutzmann, Rita, 2006, "Argentina de 1983 a 2005: de la esperanza a la desilusión», Insula. Revista de letras y ciencias humanas, Madrid, $\mathrm{n}^{\circ} 711$, febrero 2006, p. 4-5.

Heker, Liliana - Cortazar, Julio, "Polémica sobre el exilio», Cuadernos Hispanoamericanos, Madrid, n517-519, julio-septiembre 1993, p. 590-604.

Jara, Sandra, 1996, «Escritura, sexualidad y erotismo en Canon de alcoba de Tununa Mercado ", CELEHIS. Revista del centro de letras hispanoamericanas, Universidad Nacional de Mar del Plata, vol. 3, n 6-7-8, p. 417-423.

Jara, Sandra, 2005-2006, «Escribir(se) fuera de los límites (sobre En estado de memoria de Tununa Mercado)», Cuadernos del CILHA, n 7-8, 2005-2006, p. 7-16.

Jitrik, Noé, 1987, La memoria compartida, Buenos Aires, Centro Editor de América Latina.

Lagmanovich, David, 1996, "Hacia una teoría del microrrelato hispanoamericano", Revista Interamericana de Bibliografía, Washington D.C., vol. XLVI, n 1-4, 1996, p. 19-37.

Online: http://www.cidi.oas.org/Epplerib96.htm

Ludmer, Josefina, 1985, «Las tretas del débil», La sartén por el mango: Encuentro De Escritoras Latinoamericanas., Puerto Rico, Ediciones El Huracán, p. 47-59.

Mercado, Tununa, 1994, Canon de alcoba, Caracas, Monte Ávila Editores Latinoamericana. 
Morello-Frosch, Marta, 1987, «Biografías fictivas: formas de resistencia y reflexión en la narrativa argentina reciente», in D. Balderston, D. W. Foster, T. H. Donghi, F. Masiello, Ficción y política. La narrativa argentina durante el proceso militar, Buenos Aires-Madrid, Alianza Editorial, p. 60-70.

Piglia, Ricardo, 1980, Respiración artificial, Buenos Aires, Editorial Sudamericana.

Reati, Fernando, 1992, Nombrar lo innombrable. Violencia política y novela argentina: 1975-1985, Buenos Aires, Legasa, 1992.

Rocha, Carolina, 2001, "Violencia política y trauma en En estado de memoria, de Tununa Mercado», L'ordinaire latino-américain, Université de Toulouse-Le Mirail, 2001, p. 19-26.

Salvador, Álvaro, 1995, «El otro boom de la narrativa hispanoamericana: los relatos escritos por mujeres en la década de los ochenta", Revista de crítica literaria latinoamericana, Lima-Hanover, año 21, n 41, p. 165-175.

Sarlo, Beatriz, 1987, «Política, ideología y figuración literaria», in D. Balderston, D. W. Foster, T. H. Donghi, F. Masiello, Ficción y política. La narrativa argentina durante el proceso militar, Buenos Aires-Madrid, Alianza Editorial, p. 30-59.

Spiller, Roland (ss dir.), 1993, La novela argentina de los años 80, Frankfurt am Main, Vervuert.

Weigel, Sigrid, 1986, "La mirada bizca: sobre la historia de la escritura de las mujeres », in Gisela Ecker (ss dir.), Estética Feminista, Barcelona, Icaria, p. 69-98.

\section{Entrevistas}

Collette, Marianella, 2007, Grafemas. Boletín de la AILCFH, febrero 2007.

Online: http://www.utpa.edu/dept/modlang/grafemas/febrero_07/collette1.html Plante, Alicia, 2006, "Eros anda suelto», in Página/ 12, suplemento Radar Libros, Buenos Aires, domingo 11 de junio de 2006.

Online: http://www.pagina12.com.ar/diario/suplementos/libros/ 10-2108-2006-06-16.html

\section{Obra de Tununa Mercado}

1967: Celebrar a la mujer como a una pascua, La Habana, Casa de las Américas.

1988: Canon de alcoba, Buenos Aires, Ada Korn Editora.

1990: En estado de memoria, Buenos Aires, Ada Korn Editora.

1994: La letra de lo mínimo, Buenos Aires, Beatriz Viterbo.

1996: La madriguera, Buenos Aires, Tusquets.

2003: Narrar después, Buenos Aires, Beatriz Viterbo.

2005: Yo nunca te prometí la eternidad, Buenos Aires, Planeta. 